\title{
An Investigation of the Psychometric Properties of the Strong Brand Questionnaire in Sport
}

\author{
${ }^{1}$ Mona Rezaei* ${ }^{1}$ Fatemeh Kiani \\ ${ }^{1}$ Department of Physical Education and Sport Sciences, College of Human Science, Saveh Branch, Islamic Azad \\ University, Saveh, Iran.
}

\begin{abstract}
Background. Building strong brands has become a marketing priority for many organizations. The brand is an important criterion for the marketing situation. Power of brand effects on customer maintenance, financial benefit, brand broadening, and rivalry advantages... and is a concept, which was made by the consumer. The presumption is that building a strong brand yields a number of marketing advantages. Objectives. The purpose of this study was to investigate the psychometric properties of the strong brand questionnaire among the consumers of sports products. Methods. The questionnaires were administrated to 340 customers. The psychometric properties were determined based on the appropriate statistical methods. Results. The results obtained from the factor analysis via varimax rotation indicated the five factors of the strong brand scale, The relationship between 4 scales on the first scale were more than $0.49,4$ scales on the second scale were more than 0.46 , and 4 on the third scale were more than $0.57,5$ scales on the fourth scale were more than 0.33 , and 6 scales on the fifth scale were more than 0.35 , which later fitted the confirmatory factor analysis. According to conformity indicators for brand strength, the first factor was brand development, the second factor was brand identity, and brand image, brand personality and brand equity respectively were the third to fifth factors. The reliability coefficients of the internal consistency including Cronbach's alpha was satisfactory for elements and factors (0.859). Conclusion. According to the estimated psychometric properties, this instrument can be used by the researchers in order to assess the achievement goals orientations among the sports product's customer.
\end{abstract}

\section{KEY WORDS: Reliability, Strong Brand, Sport Brands, Psychometric, Sport Customers.}

\section{INTRODUCTION}

The importance of intangible assets in the effectiveness of the organization's activities and financial performance of businesses in the creation and survival of organizations, companies and different industries is obvious to everybody. In competition era based on knowledge the ability of organizations to develop and mobilize creating the greatest intangible assets and organic growth for its owners or shareholders and at least constitute half of the company's market value. Intangible assets are long-lived and intangible assets which developed by a company or organization. The brand is one of the most important intangible assets. Commercial name or Brand is a name, phrase, term, sign, symbol, design or combination of them in order to

*. Corresponding Author:

Mona Rezaei

E-mail: mona8059@gmail.com 
introduce products and services to sellers or group of sellers and distinguish them from competing firm's products. According to Aaker research results, the top brand for customer subconsciously means better quality product $(1,2)$. Nowadays sport managers' use of marketing strategies, especially customer-centric strategies. In fact the purpose of managers to adopt these methods is increase the strength and popularity of the brand among customers and motivates the sense of obligation and loyalty (3). According to research results of Robichaud et al. (2012) one of the prerequisites for the success of the brand is its strength(4). Acker believes a strong brand means having a better quality of products / services for customers. The customer buys a product that paying more and then received better products (5). According to Keller (1993) more strong and more successful brand penetrating the hearts and minds of customer. A strong brand structure Require brand awareness, brand loyalty and perceived quality of the brand. Customer after ensure the quality of the brand remains faithful to it. Furthermore a strong brand is the most important factor to select it by customers (6).

Over the past 20 years, creating strong brands has become one of the most important organizational aims. In this regard brand strategies development known as an effective way to increase the quality of products / services brand (7). The elements of most strong brands include: brand identity, brand personality, brand development, brand image and brand equity $(1,3$, 8-10).

Strong and successful brands raised the organization and develop it. It also highlights the way and activities of the organization. Top brands can influence the feelings, emotions and spirit of the consumers and lead to a successful sales of a product. Over time, consumers trust the brand and recommend it to others. The purpose of creating a brand even more than the sale of a products and services, and sometimes they can affect share of the market and proposed solutions for business. And even become to the integrity of the organization and attract people and kept customers and shareholders and create the value. The remarkable thing is that after creating a brand, organization behavior and its action could lead to create a strong and popular brand. In today's world by development of information, every move and decision-making organization is assessed by brand. Nowadays, brand is considered as investment for many businesses and brand equity and reputation of an organization is Several times more than the value of tangible and visible assets. On the other hand brand is mental and spiritual movement which should be in the minds of buyers. Brands are social character and a brand will be successful if People have the sense of belonging and ownership to it (11).

Discussion about brand in sport is considered necessary with huge amounts of investment in Sports industry $(12,13)$. Moharam zadeh and Akbari (2013), investigate the relationship between the dimensions of customer loyalty and brand strength in Iran's national football and volleyball professional leagues. They collected the data though brand loyalty questionnaire Dr Moghimi brand, and distributed this questionnaire to managing directors, public relations, finance manager and coach of professional football and volleyball teams in Iran league. The results showed a significant positive relationship between the level of customer loyalty and national brand strength (14). Heidarzadeh et al (2010) investigated the effect of brand strength based on the level of mental preparedness of 280 customers to buy by valid and reliable questionnaire and structural equation modeling concluded that brand strength have positive effect on customer mentally prepared to purchase decision (15). Balali and et al (2012) investigate the role of brand strength in purchase decision exclusively among luxury cars customers in Iran. First, they examined supply and demand trends of the car according to taste of customers and other affecting factors on purchase decision with the help of library resources and interviews with experts. The results show that, because of the high tariffs and low diversity of imported products, automotive assembly inside, with broader service coverage, lower tariffs and less expensive parts have better market (16).

Regarding the role and importance sport in the economy and culture, etc., and the lack of means that can measure the effectiveness of brand strength in the sports industry, the necessary assess and measure this important element is become clear. It can be said necessity of systematic and purposeful strong brand in sports, after understanding the importance of it, is access 
to a tool that be effective on Identifying marketing factors. Regarding to this and in accordance with the literature, this study examined the psychometric properties of the questionnaire in sports strong brand.

\section{MATERIALS AND METHODS}

Research Design. This research process used the descriptive research design. Data collected through a survey technique using a questionnaire to the respondents. The data was then processed using LISREL (8.7) and SPSS (21.0) software.

Data Collecting and Sampling. In this study, researcher used quantitative data to obtain primary data. Quantitative data was obtained through field research (surveys) using a questionnaire filled out by the respondents. The sample of this research is consumer of sport's brands. The research survey used simple random sampling method. Totally 350 questionnaires sheets were issued and 340 valid questionnaire ones were revoked. The sampling technique used by the researcher is convenience sampling. The convenience sampling technique is sampling in which the researcher selects a sample of population members that is easily accessible by researchers; in other words, respondents were chosen by the researcher because they are at the right place and time appropriate with this study area. In this study, the researcher used convenience sampling to get the respondents. $20 \%$ of respondents have experienced the brand at least 3 years, $30.88 \%$ between 3 and 5 years, $31.18 \%$ between 6 and 9 years, $9.71 \%$ between 10 and 13 years and $8.24 \%$ more than 13 years.

Instrument. The research tool consists of a researcher-made questionnaire on a powerful brand in sport. In order to finalize the questionnaires using the classical theories, the following measures have been taken: Analysis of questions; testing the reliability of the test; Testing the validity of the test. Structural validity has been investigated through confirmatory factor analysis (first order). Content and formalism validity was used by experts and university professors in the field of business management and sports marketing management. The current questionnaire consists of 23 items and 5 subscales of brand value, brand identity, brand image, brand personality and brand development. The respondents answered the questions into the Likert five-point scale from "agree" to "disagree", which have been given their value from " 5 " to " 1 " for the related data analysis.

Reliability of the instrument. The reliability of the study was calculated by Cronbach's alpha that the coefficient reported 0.859 . To estimate the reliability of the statistical characteristics of questions was used a series that requires only one test form implementation. The correlation of each item calculated and reported by total score of questionnaire which all showed the desirability of question acceptance coefficients between 0.847 and 0.860 . The reliability of the questionnaire was also recalculated after the removal of each item. When the item are removed, the amount of reliability of the questionnaire reduced or does not show a significant changes. This showed the desire to measure this item for strength of a brand. It should be noted that calculating the reliability of the questions have been made after confirmatory factor analysis.

\section{RESULTS}

Exploratory factor analysis. To discover the most powerful elements of a strong brand, first used exploratory factor analysis. According to the significance level (0.01), KMO test (0.839) and Bartlett's test significant five factors were obtained, and regarding to sampling adequacy and Bartlett's test of significance, the correlation matrix data suitable for factor analysis and performance factor analysis based on the correlation matrix of the study will be justified. All related values associated with the test questions along with main centered factor are higher than 30.0 that shows the high correlation between the factors of the test and its suitability for factor analysis. To reduce the variance between factors, questions more than a factor loadings above 4.0, were removed. Based on the percentage of variance factors and Scree Plot (1), five factors were selected and rotate by varimax. The second stage of the factor analysis is relating to the extraction of primary factors. To determine which test consisted of what factors, the primary factors are derived from questionnaire. 


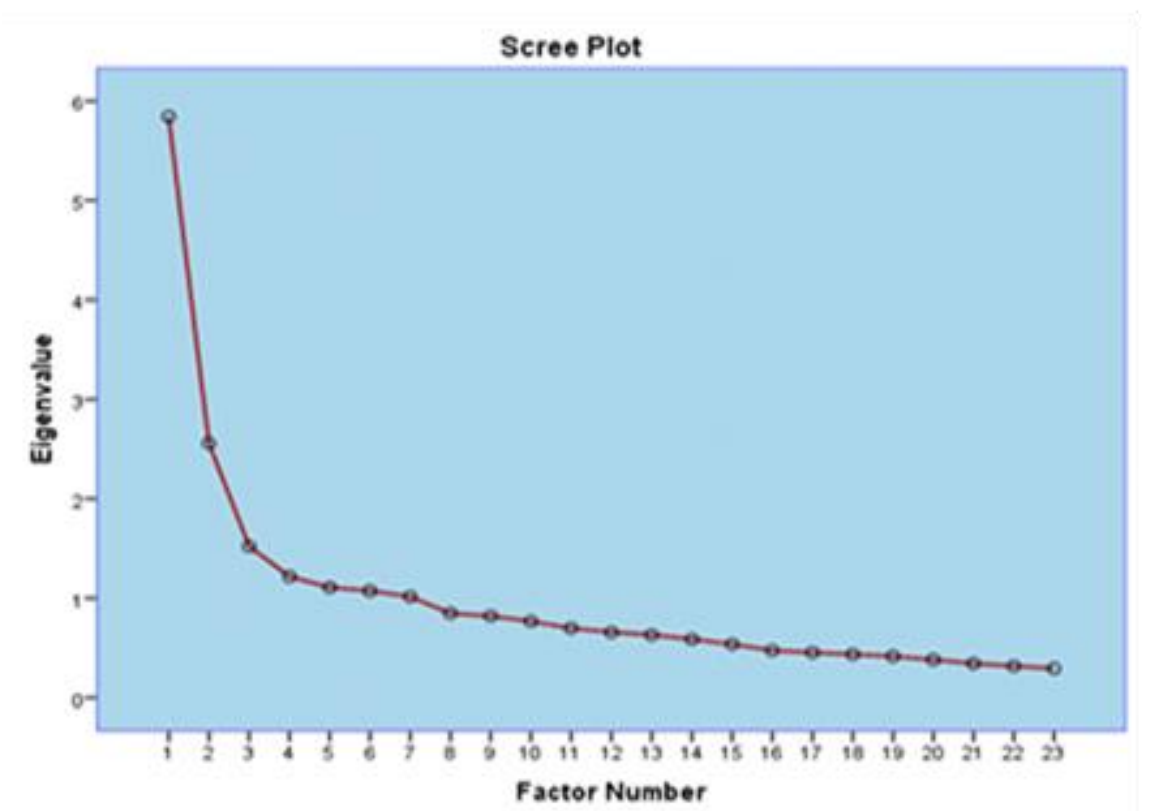

Figure 1. Scree plot to find the number of factors for strong brand.

To extract the factors from the correlation matrix used of main centered factoring method because the aim was to explain the variance in the correlation matrix. To determine appropriate rotation, Kaiser Criterion and the Scree test was evaluated. According to the Kaiser criteria, the factors that have equity higher than one can be extracted as factors. According to the results, the equity of 5 factors is more than one which generally is $40.89 \%$ of the total variance. $10.78 \%$ of the total variance is explained by the first factor, 9.78 Percent explained by the second factor, $8.66 \%$ explained by the third factor, 6.79 percent explained by fourth factor and 4.86 percent explained by fifth factor.

With precision in Figure 1 can be found that 5 factor of set of factors that make up the questionnaire are higher than slope of the line and other factors are almost in the same range and close together. It can be concluded that 5 factors of the present study are constructive research tool. Then 5 factors of questionnaires are extracted and examined before rotation. According to the results, a total factor appeared first and most of the questions are emphasized on them. Because the matrix factor not rotate and the factor did not get meaningful structure, it was decided to use varimax rotation method. Data Factor matrix after thirteen experiment rotation has the best combination of structure and questions. Generally, after varimax rotation of strong brand, 4 indicators correlated with the first factor and higher than 0.34. Indicators of Question 41, has the highest correlation with the first factor And the lowest correlation is related to indicators' of question 44. Totally of 4 questions on second factor have 0/46 load factor, 4 indicator on third factor have the load factor higher than $0.57,5$ indicator on fourth factor have the load factor higher than 0.33 and 6 factor on fifth factor have the load factor higher than 0.35. Compliance indicators with pre considered factors of a strong brand show that the first factor can be named "brand development" factor and the second factor named "Brand Identity" and the third factor named "brand image", the fourth named "Brand personality" and the fifth factor named "brand equity ".

Confirmation factor analysis - first order(Structural validity). According to this exploratory factor analysis on items of this questionnaire, all items were used in 5 factors: "brand equity", "brand personality," "brand image," "brand identity" and "brand development". To achieve the desired validity of the sample, confirmatory factor analysis and LISREL software (8.7) was used. In Table 1, reported the parameters measured for each question. 
Table 1. the parameters of confirmatory factor analysis of strong brand

\begin{tabular}{|c|c|c|c|c|c|c|c|c|c|c|}
\hline factor & elements & question & $\beta$ & $\mathrm{t}^{* *}$ & $\begin{array}{c}\text { Squared } \\
\text { multiple } \\
\text { correlation }\end{array}$ & elements & question & $\beta$ & $\mathrm{t} * *$ & $\begin{array}{c}\text { Squared } \\
\text { multiple } \\
\text { correlation }\end{array}$ \\
\hline \multirow{12}{*}{ 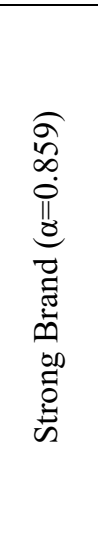 } & & 6 & 0.25 & 4.43 & 0.06 & \multirow{7}{*}{ 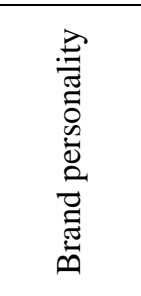 } & 19 & 0.75 & 14.78 & 0.56 \\
\hline & 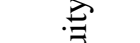 & 13 & 0.48 & 8.8 & 0.23 & & 20 & 0.71 & 13.97 & 0.51 \\
\hline & $\vec{\sigma}$ & 25 & 0.32 & 5.72 & 0.1 & & 22 & 0.47 & 8.56 & 0.22 \\
\hline & $\bar{E}$ & 31 & 0.47 & 8.73 & 0.22 & & 27 & 0.58 & 10.93 & 0.34 \\
\hline & స్ల & 39 & 0.62 & 11.75 & 0.38 & & 32 & 0.59 & 11.07 & 0.34 \\
\hline & & 48 & 0.55 & 10.42 & 0.31 & & 38 & 0.64 & 12.34 & 0.41 \\
\hline & \multirow{4}{*}{ 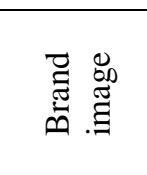 } & 7 & 0.63 & 11.16 & 0.39 & & 40 & 0.56 & 10.47 & 0.31 \\
\hline & & 8 & 0.61 & 10.88 & 0.37 & \multirow{5}{*}{ 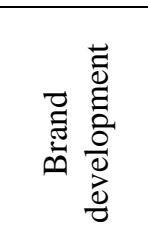 } & 41 & 0.77 & 15.41 & 0.59 \\
\hline & & 9 & 0.64 & 11.46 & 0.41 & & 42 & 0.78 & 15.57 & 0.61 \\
\hline & & 10 & 0.72 & 13.25 & 0.52 & & 43 & 0.67 & 12.99 & 0.45 \\
\hline & \multirow{2}{*}{ 芯 } & 16 & 0.64 & 12.04 & 0.4 & & & & & \\
\hline & & 18 & 0.75 & 14.83 & 0.56 & & 44 & 0.57 & 10.48 & 0.32 \\
\hline
\end{tabular}

According to the results, root mean square of approximately was 0.073 , softened fitting Indicators was 0.95 , goodness of fit indicator was 0.93, Significant of chi-square statistic was $1015.92(\mathrm{p}=0.001)$. All indicators are very favorable and fit the data model and this represents a consistent of items to theoretical construct.

In Table 2, the fitting indices of the measurement model are reported.

Table 2. Fitting indices of the measurement model

\begin{tabular}{cccccccc}
\hline Indicators & $\chi 2(\mathrm{p})$ & RMSEA & NFI & NNFI & CFI & GFI & AGFI \\
\hline Fitting indices & $1015.92(0.001)$ & 0.073 & 0.93 & 0.95 & 0.97 & 0.93 & 0.9 \\
\hline
\end{tabular}

According to table 2, all indicators are reported to be highly desirable, and the model with data is very fitting and this indicates that the points are consistent with the theoretical construct. In Fig. 2, the firstorder confirmatory factor analysis, including factor loads and their error rates, is presented.

\section{DISCUSSION}

The role and importance of marketing and the active participation of customers with the brand in the modern world, create the requirement to achieve a valid measurement tools to assess these variables for sports customers. According to main purpose of this study that is evaluate the psychometric properties scale of a strong brand and evaluate each item according to the load factor and Cronbach's alpha and its content items, finally, led researchers to creation 5 subscales. Each 5 subscales are sufficiently valid that can be regarded as factors affecting a strong brand. The content validity analysis of this scale represents the value of their exploration and their presence in the questionnaire as structures explain that they should be evaluated even further in future research. The scale validity is reported 0.859 that indicates the desirable amount of it.

In analysis of the main factors 5 Subscale of sampling adequacy size (KMO) was reported 0.839. Cerney \& Kaiser (1977) believe, Factor analysis can be done When the value of KMO is bigger than 0.6. And whatever this amount is higher; the sampling adequate and appropriate will be higher (17). According to the amount of adequacy of sampling, all subscales have a high positive correlation to strong brand questionnaire. The research results are in accordance with the findings of Jana et al, 2014 And Viot, $2011(3,9)$. 


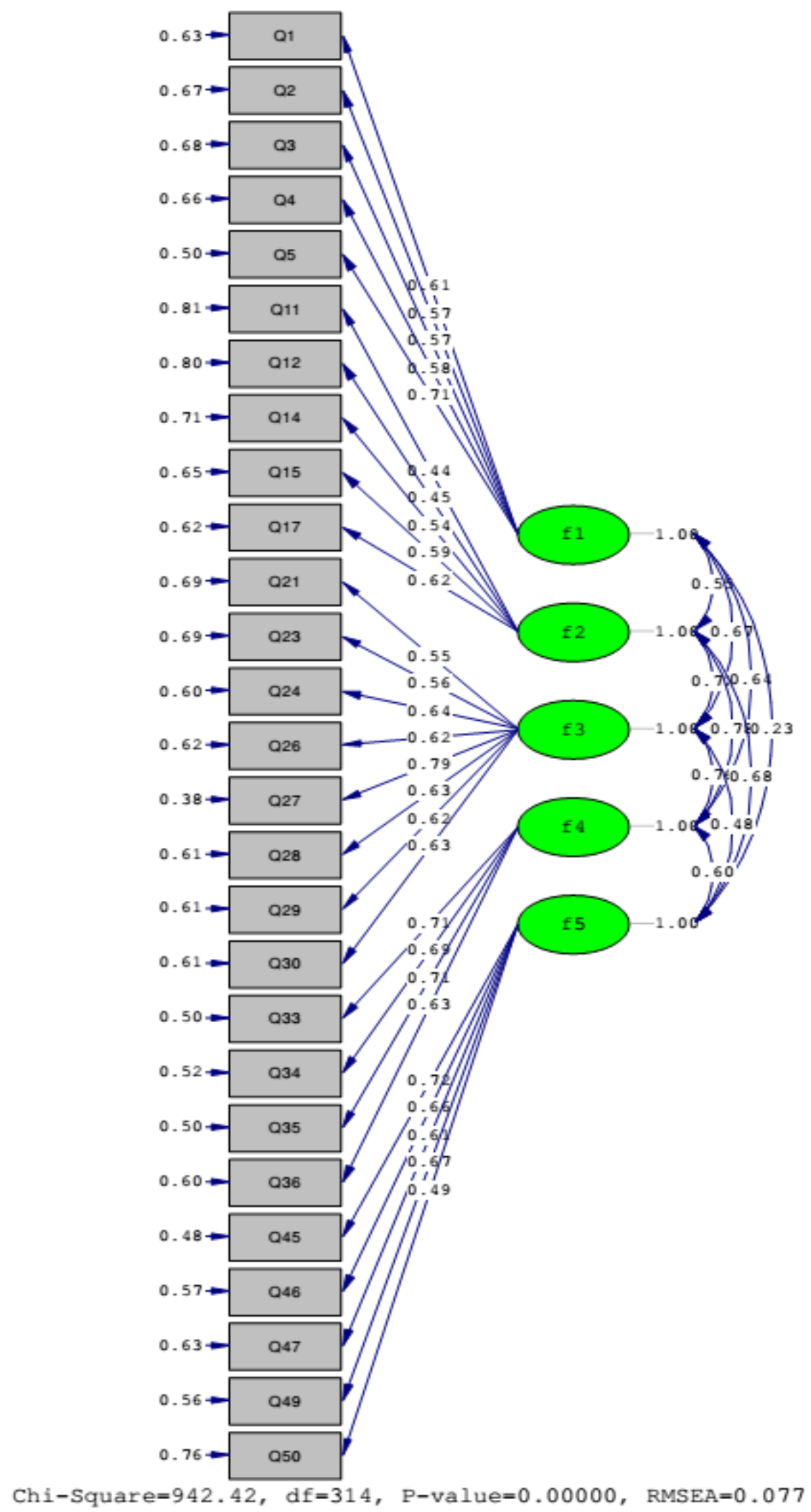

Figure 2. Confirmatory factor analysis, including load factors and their error rates. 
Munro (2005) stated that in confirmatory factor analysis, theoretical models have been compared to each other and In fact confirmatory factor analysis is a useful way to review the questionnaires (14). According to research results GFI and AGFI indicators are greater and equal to 0.90 and RMSEA is smaller than 0.1. Bentler and Bonnet (1980) sated when indicators goodness of fit and adjusted goodness of fit is more than 0/90, The analysis show a good fit of the model. Also when the square root of the variance estimation error is approximately less than 0.10 analysis reports Acceptable fit (18). The confirmatory factor analysis showed the numerical values between indicators of factor loadings and factors that lead to the weight of beta (5). The basis for any research is using the reliable tools. The reliability for this questionnaire is 0.859 that Indicating high internal consistency. This result indicates that a strong brand questionnaire is a reliable tool that will help the sport researchers to assess the strength of sports brands. Kim (2010) in a study on athletes gets the $0 / 870$ for questionnaire reliability (6). Baeve (2011) in his master's thesis investigate the strength of the brand (19). According to Herbest \& Merz (2011) research results the questionnaire Reliability components of Brand Strength were reported higher than 7.0 (20). Baumgarth \& Schmidt (2010) reported the reliability of the components of Brand Strength higher than 8.0 (12). In exploratory factor analysis, scree test suggested the Five-Factor Model. In confirmatory factor analysis gain the highest fitting for this model too. As a result, the factor structure, creating five factors is consistent and compatible with the results of Aaker (1999), Keller (2001), and Baeva (2011) $(19,21,22)$. On the other hand to assess questionnaire items were used the appropriateness of some parameters such as standardized factor loadings and squared multiple correlations. After removing the common loading factors appear acceptable level for all items and any items could explain a part of the total variance in each subscale. $\mathrm{T}$ test results of factor analysis indicated that all the questions (items) have the strength to predict their factors, Such that 4 Indicators of Brand development Have a correlation higher than 0.34 . Overlay 4 questions on brand identity have a load factor higher than 0.46 . While 4 Indicators on brand image have the load factor higher than 0.57 and 5 factors on Brand personality have a load factor higher than 0.33 and 5 factors brand equity have a load factor higher than 0.35. Also $\mathrm{T}$ values between questions and structures in all Items were statistically significant and this means that there is a logical relationship between questions and related structures. Furthermore, the values of $\mathrm{T}$ indicated that all questions are actually measure the action of related structures and the brand questionnaire has validity.

\section{CONCLUSION}

Finally, based on the findings of the study, questionnaire of strong brand is reliable and valid scale for Sports brands. In addition, the researchers interested in the field of sport science can be used the questionnaire of strong brand as a useful tool in sport and acquire acceptable results. The use of this questionnaire can be a key to many researches which measure the factors related to the brand, marketing and customer preferences Products / Services in sport is important.

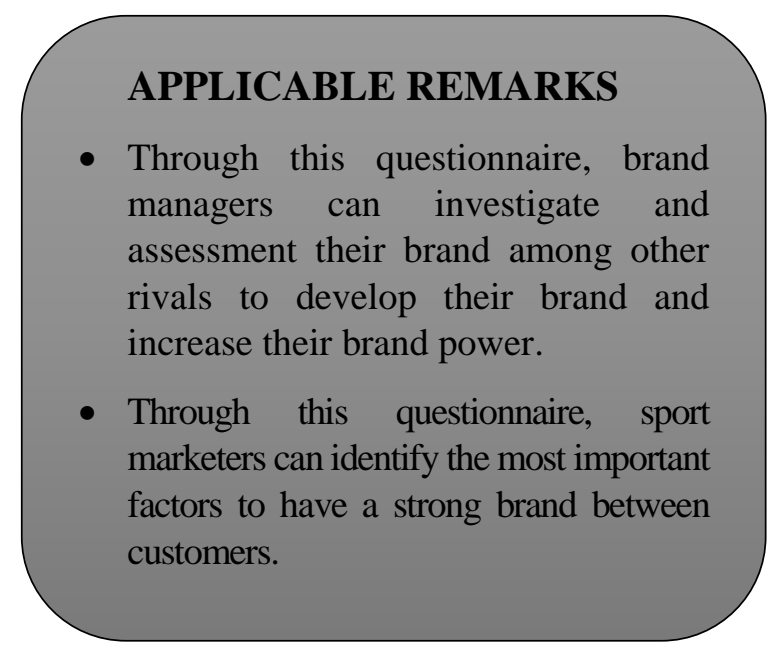

\section{REFERENCES}

1. Aaker DA. Managing Brand Equity, New York, Maxweel Macmillan-Canada. Inc; 1991.

2. Mühlbacher H, Raies K, Grohs R, Koll O. Drivers of brand strength: Configural paths to strong cognitive brand equity. Journal of Business Research. 2016;69(8):2774-80. 
3. Jana S, Das JR, Dash M. Modeling brand personality using structural equation modeling. International journal of marketing and technology. 2014;4(8):1.

4. Pettit R, Cook W, Belmont D, Sokolyanskaya I. Experiential marketing: a master of engagement. ARF Event Engagement Consortium. 2008.

5. Aaker DA. Measuring brand equity across products and markets. California management review. 1996;38(3).

6. Kim Y. The effects of virtual sport experience on brand attitude and attitude strength. 2010.

7. Popp B, Woratschek H. Introducing branded communities in sport for building strong brand relations in social media. Sport Management Review. 2016;19(2):183-97.

8. Aaker DA, Joachimsthaler E. Brand leadership: Simon and Schuster; 2012.

9. Viot C. Can brand identity predict brand extensions' success or failure? Journal of product \& brand management. 2011;20(3):216-27.

10. Robichaud F, Richelieu A, Kozak R. Branding as a communications strategy: A framework for desired brand identity. Journal of brand management. 2012;19(8):712-34.

11. Fournier S, Breazeale M, Avery J. Strong brands, strong relationships: Routledge; 2015.

12. Baumgarth C, Schmidt M. How strong is the business-to-business brand in the workforce? An empirically-tested model of 'internal brand equity'in a business-to-business setting. Industrial Marketing Management. 2010;39(8):1250-60.

13. Zhang Y. The impact of brand image on consumer behavior: a literature review. Open journal of business and management. 2015;3(1).

14. Munro BH. Statistical methods for health care research: lippincott williams \& wilkins; 2005.

15. Heidarzadeh K, Alvani SM, Ghalandari K. Investigation the Effect of Brand Social Power Dimensions on Purchasing Decisions Based on Customers' Subjective Readiness Levels. Management researches. 2010;86(21):27-52.

16. Balali M, Aghazadeh H, Ahmadi S. The Role of Brands in Purchasing Luxury Auto. Business Management. 2012;14(4):1-20 [Article in Farsi].

17. Cerny BA, Kaiser HF. A Study Of A Measure Of Sampling Adequacy For Factor-Analytic Correlation Matrices. Multivariate Behav Res. 1977;12(1):43-7. Epub 1977/01/01.

18. Bentler PM, Bonett DG. Significance tests and goodness of fit in the analysis of covariance structures. Psychological bulletin. 1980;88(3):588.

19. Baeva DY. Strong brands: how brand strategy and brand communication contribute to build brand equity: the case of navigator 2011 .

20. Herbst U, Merz MA. The industrial brand personality scale: Building strong business-to-business brands. Industrial marketing management. 2011;40(7):1072-81.

21. Keller KL. Building customer-based brand equity: A blueprint for creating strong brands: Marketing Science Institute Cambridge, MA; 2001.

22. Aaker JL. The malleable self: The role of self-expression in persuasion. Journal of marketing research. 1999:4557. 